\title{
AOR
}

Selected Papers of \#AolR2019:

The $20^{\text {th }}$ Annual Conference of the Association of Internet Researchers Brisbane, Australia / 2-5 October 2019

\section{THE CONCEPT OF 'SHARING' IN CHINESE SOCIAL MEDIA}

\author{
Luolin Zhao
}

School of New Media, Peking University

Nicholas John

Department of Communication and Journalism, The Hebrew University of Jerusalem, Israel

In the context of the internet, the concept of 'sharing' is a central and powerful metaphor (John, 2013, 2016; Kennedy, 2016). It reflects and constructs the ideal type of relations between users - relations based on honesty, mutuality and openness. However, the semantic spheres of meaning that give 'sharing' its contemporary force are profoundly Western and rooted in the English language. The concept of 'sharing' as used in Western social network sites (SNSs) 'works' because it appeals to a sense of equality, because it refers to the digital transfer of information, and because it is a cultural type of talk (Carbaugh, 1989) through which we know ourselves and others; in other words, it appeals to a certain self and makes assumptions about how that self knows itself and maintains ties with others. This self has been defined as a 'therapeutic self' (Füredi, 2004). Yet this does not necessarily apply outside Western cultures, raising the possibility that work on 'sharing' to date is Western centric and should be dewesternized (see esp. Park \& Curran, 2000; Waisbord \& Mellado, 2014). Indeed, as argued in cross-cultural pragmatics (Wierzbicka, 2003), language encodes cultural differences; thus, even though American and Chinese social media users appear to be doing more or less the same things online-posting content, writing messages, uploading videos, etc.- - the fact that their participation has different names-sharing in the US, and fenxiang in China-implies that it may also have different meanings.

Fenxiang and gongxiang-the Mandarin words for 'sharing'-are central words in the context of Chinese social media and have profound socio-cultural connotations, though different meanings and implications. With over 2,000 years of history, gongxiang is closely related to Confucian thought and has been employed continuously by Chinese rulers as the term for a political ideal of harmony, while at the same time it has more recently become the technical word for sharing in computing fields (time-sharing, fileZhao, L. and John, N. (2019, October 2-5). The Concept of Sharing in Chinese Social Media. Paper presented at AolR 2019: The $20^{\text {th }}$ Annual Conference of the Association of Internet Researchers. Brisbane, Australia: AolR. Retrieved from http://spir.aoir.org. 
sharing, etc.). Fenxiang, on the other hand, refers to sharing on an interpersonal level, its meaning having shifted from physical division to communication (somewhat like the English word 'sharing'; see John, 2016). It has also come to refer to the communication of one's feelings in the therapeutic mode, starting from when China began to import therapeutic practices from the West in the 1990s (Hsuan-Ying, 2018).

Given quite separate processes of language development, along with different construals of selfhood in the West and China (Yan, 2017), we ask: what connotations do the Mandarin equivalents of 'sharing' bring with them to the sphere of social media? How do they reflect the Chinese context, and how, historically, have they come to discursively construct social media in China?

Following John's (2013) study of changes to the word 'sharing' in English-language SNSs, this study also uses web archive analysis to understand the historical transformation and the current role and rhetoric of fenxiang and gongxiang in the context of the Chinese Internet. We used the Wayback Machine to gather historical data from 32 Chinese SNSs to track changes to the deployment of fenxiang and gongxiang by the SNSs themselves in their self-descriptions and explanations of what one can do on the site. We first located the earliest archived front page of each SNS, then downloaded screenshots through to May 2018. Over 5,000 screenshots of those archived web pages were analyzed and coded.

We find that the Chinese translations for sharing—fenxiang and gongxiang-are indeed both keywords in Chinese SNSs. Since 2006, fenxiang has become the umbrella word to denote participation in SNSs, which overlaps with John's findings about the word 'sharing' being adopted by SNSs most intensively around 2005-2007. Most sites established after 2008 launched with fenxiang in their taglines or self-descriptions. Its usage is close to sharing in Western social media, and displays similar trends to 'sharing' in that over time it begins to appear with fuzzy objects of sharing, such as 'your life', and with no object of sharing (see John, 2013). Gongxiang, on the other hand, which is the other translation for 'sharing', has a twofold meaning. While it is normally used for its technical meaning in contexts such as file-sharing, it is also deployed in SNSs' mission statements regarding their ultimate goal of building a harmonious community.

However, despite some similarities with the Western notion of 'sharing', fenxiang and gongxiang actually draw on Chinese versions of selfhood and relations between the self, others and society, as well as reflecting the interplay between the individual, social media, and the state (Liu, 2011; Yang, 2012; Zhang, 2018). In both cases, our observations of 'sharing' on Chinese SNSs resonate with the notion of "the divided self", understood as the concomitance of a collectivist self and an individualized self in postreform China (Kleinman et al., 2011), and relate to the deep roots of the words in Mandarin.

What we ultimately see in fenxiang/gongxiang is the convergence and mystification of social media platforms' interests and responsibilities: Chinese SNSs attempt to attract users while adhering to state discourses. Positioned between the state and individual 
users, SNSs seek to maintain a harmonious cyberspace in compliance with the duty of corporate citizenship, while at the same time attracting users and motivating them to produce ever more content and data in accordance with the SNSs' commercial aims. The rhetoric of fenxiang/gongxiang enables them to do just this. Associated with positive values such as friendship, joy, wonder, and knowledge, the rhetoric of fenxiang encourages users to post positive content and to foster positive relationships. Likewise, appropriated by the state as a political ideal of harmony, gongxiang extends desirable prospects but also unavoidable responsibilities to social media companies. While for users gongxiang represents a form of resource sharing, platforms adopt its rhetoric to display their compliance with the state. In this way, fenxiang and gongxiang become the lens through which to observe the subtlety, complexity and idiosyncrasies of the Chinese internet.

\section{References}

Carbaugh, D. (1989). Fifty terms for talk: A cross-cultural study. In S. Ting-Toomey \& F. Korzenny (Eds.), International and Intercultural Communication Annual (Vol. 13, pp. 93-120).

Füredi, F. (2004). Therapy culture: Cultivating vulnerability in an uncertain age. London: Routledge.

Hsuan-Ying, H. (2018). From psychotherapy to psycho-boom: a historical overview of psychotherapy in China. In D. E. Scharff (Ed.), Psychoanalysis and Psychotherapy in China (pp. 1-30). London: Routledge.

John, N. A. (2013). Sharing and Web 2.0: The emergence of a keyword. New Media \& Society, 15(2), 167-182. doi:10.1177/1461444812450684

John, N. A. (2016). The Age of Sharing. Cambridge: Polity.

Kennedy, J. (2016). Conceptual boundaries of sharing. Information, Communication \& Society, 19(4), 461-474. doi:10.1080/1369118X.2015.1115888

Kleinman, A., Yan, Y., Jun, J., Lee, S., \& Zhang, E. (2011). Deep China: The moral life of the person: Univ of California Press.

Liu, F. (2011). Urban youth in China: Modernity, the Internet and the self. New York, London: Routledge. 
Park, M.-J., \& Curran, J. (2000). De-Westernizing media studies: Psychology Press.

Shi-xu. (2014). Chinese discourse studies. Basingstoke: Palgrave Macmillan.

Waisbord, S., \& Mellado, C. (2014). De-westernizing communication studies: A reassessment. Communication Theory, 24(4), 361-372.

Wierzbicka, A. (2003). Cross-cultural pragmatics (2nd ed.). Berlin, New York: Mouton de Gruyter.

Yan, Y. (2017). Doing Personhood in Chinese Culture: The Desiring Individual, Moralist Self and Relational Person. The Cambridge Journal of Anthropology, 35(2), 1-17.

Yang, G. (2012). A Chinese Internet? History, practice, and globalization. Chinese Journal of Communication, 5(1), 49-54.

Zhang, L. (2018). Cultivating the therapeutic self in China. Medical anthropology, 37(1), 45-58. 